\title{
DISTINCTION AND DIFFERENCE: \\ REVISITING THE QUESTION OF TASTE ${ }^{1}$
}

\section{Juliane Rebentisch}

\begin{abstract}
The essay discusses the logic of distinction under the sign of the contemporary culture of difference and proposes a discussion of the relationship between taste and contemporary art. The recent trend toward greater individualization might have rendered social codes more permeable. But this state of affairs is neither the opposite of the standardization nor does it imply that the social logic of distinction has been suspended. It has merely undergone further differentiation, but without abolishing the signifiers of status. On the one hand art as a commodity partakes in the respective developments, on the other, certain strands in contemporary art can also be read as opposing the subject of aesthetic experience to the subject of consumerist taste.
\end{abstract}

\section{KEYNOTES}

Consumption, Self-Marketing, Individualization, Style, New Forms Of Distinction, Choice, Contemporary Art, Aesthetic Autonomy, Aesthetic Judgment

One of the most memorable passages in Pierre Bourdieu's Distinction: A Social Critique of the Judgment of Taste concerns the fate art suffers at the moment that it becomes the property of the "dominant fractions." It then joins all the other luxury goods that are meant to convey their owner's exquisite taste: the jewelry, the furs, the perfume, the furniture, the fancy china and opulent silverware, the library with its first editions, the limousine, the designer fashions, the wine cellar, etc. Although the consumption of art appears in this regard as merely one practice of distinction among others, the very purposelessness of art proves most suitable to the purposes of those who wish to decorate their lives with it. For "the appropriation of symbolic objects with a material existence," such as works of art, "raises the distinctive force of ownership to the second power." Next to the inconceivable exclusivity of owning a real, let's say, Manet, any symbolic appropriation of the same work pales-it is a stale and indeed merely symbolic substitute. As property, the work of art becomes the "reified negation of 
all those who are unworthy of possessing it." Yet it takes more than just money to produce this effect. A nouveau riche who buys art as an investment or, even worse, has art consultants buy it for him incurs discredit in this regard. The owner must make the object truly his own; his possession must bespeak intimate familiarity with the thing, which presupposes education, and thus also the commitment of generous amounts of time, a notoriously scarce resource. The possession, Bourdieu writes, must attest to the quality of the appropriation. Only then does the desired fusion between possession and personality function such that the property, as Marx puts it in the Paris Manuscripts, ultimately expresses the proprietor's "personal, distinctive, and therefore essential mode of existence." Things then demonstrate not so much their own quality as rather that of the person who has appropriated them.

The literal domestication art undergoes in such appropriation may become a subject of art. Several works by American artist Louise Lawler, for example, illustrate how art curdles in such contexts into a decorative object that no longer knows any substance other than the purpose of expressing its owner's personality: a painting by Jackson Pollock communicates with the flower-patterned china soup bowl in order to embody, like the latter, the taste of the owner's subjectivity (Pollock and Tureen, 1984). It is a wellknown phenomenon that the index of the collector's personality cannot be effaced from the private art collection even when it is removed from the private interior and committed to the public hand. That is strikingly evident in the case of collections of contemporary art. For when the value of the objects contained in a collection is no longer a matter of canonical knowledge, as it seems to be with contemporary art, the collector's personality comes to the fore. $\mathrm{He}$ or she alone, his or her particular taste, is what holds the collection together. There is a whole new generation of celebrity collectors where the publicity oriented function of collecting is in the foreground. Whereas the old bourgeois collector saw his or her activities as a kind of service to the public, the new collectors use their art as a means of pursuing economic and power interests, and somewhat openly so. In the respective cases, the handing over of the collector's property to the public accordingly does not at all mean that the things become emancipated from the personal relationship that formerly determined them. To the contrary: the aim is to publicize, to publicly exhibit this personal relationship, to heighten the logic of individual distinction by extending it into the public sphere, degrading the latter into a stage for private property-and increasingly privatizing it. 
However, not least among the goals of self-projection by means of objects, it is well known, is self-marketing. The distinction someone may gain by demonstrating his or her own taste increases his or her own market value. The aim of commodity consumption, in other words, is to advertise oneself as a commodity (one's labor). None of this is new, of course; but it has taken on a novel quality in recent years. Where the so-called "new spirit of capitalism” rules (for it does not simply supplant the old one---the two coexist), it generates structures within which the objective shifts from standardizing the subjects in accordance with certain role models to exploiting their potential for deviation. In other words, it homes in on the very point that, to Hannah Arendt, for instance, still acted as the barrier to the "degradation of the human person [...] prevalent in commercial society": the fact that the person's aliveness escapes "all generalization and therefore all reification." This potentiality, the individual's excess above and beyond any concreteeconomic and/or theatrical-performance, is exactly what is now prized in the commodity that is labor. Under these conditions performance is interesting no longer primarily for its concrete utility in a particular setting, its application, and instead for what transcends that setting: the possibility of prospective actualizations, its applicability, a promise of a future. Yet for this promise to be realized as promise, the performative capacity of the subjects must be shown to possess a certain quality: it must be exhibited or staged as essentially flexible. To the extent that the performative subject is put on display, that is to say, it presents itself as a version of what it can be; the optimum version, surely, but forever only a version.

In this perspective so called selfie culture refers not least to the fact that no one of the images of the self is to assert itself as the true image; what must be demonstrated is that the subjects are one thing above all: open to the future. The potentiality of the performance then attains a virtually separate existence above and beyond its possible actualizations. The alienation that is at issue here is no longer that between subjects and things; it is one between the subject and itself-as-agent. The subject prompted to mold itself in accordance with economic criteria is restless in its pursuits, forever racing ahead of or trying to catch up with itself: such a subject knows no 'instant of fulfillment.' On the contrary, the lopsided orientation towards its allegedly endless possibilities perverts its future into a present and condemns its genuine present to an ahistorical timelessness. Here the economic consciousness already reveals itself to be an unhappy one. What is more, to the extent that the subject cannot but live in a concrete world with concrete constraints 
and accept responsibility for its actions, the postulate of lived infinity is doomed to fail. Hence the symptom of the neoliberal attempt to actually install the (self-contradictory) idea of an abstract infinity (which is historically associated with Romanticism) in the space of praxis: the perversion of the euphoric sense of possibility into a feeling of emptiness.

But there's another problem with the neoliberal ideology of the infinite self. Not only is it as Hegel had already criticized with regard to the romantics an essentially self contradictory idea, it is also highly misleading - since the openness demanded from the subjects by neoliberalism must always prove its compatibility hence it is restrained. Potentiality, under such circumstances, is subject to "modulation"; difference is domesticated. This is where selfie culture is entwined with consumerist culture, with which social networks are linked via their like economy. For consumers not only prove to be consumable themselves through their consumption. Also, the logic of ever more refined individual distinctions is itself the paradoxical effect of a similarity disclosed by algorithms. Where individuals are confronted online with offers that are beyond their usual horizons it is via the purchase behavior of comparable consumers.

However, it is also clear that inasmuch as originality, creativity, flexibility have become decisive social demands, the individual's consumer competency, which allows her or him to place her- or himself on the market in the most advantageous way possible, is less and less governed by openly predetermined social codes; his or her aim must instead be to articulate a form of self-realization that evinces the greatest possible degree of independence from external constraints. The style that best accomplishes this very contemporary condition is thus at once the negation of style-not, to be precise, of all style, but of style as a binding commitment to a unified whole. Individual style is the anti-stylistic assemblage of manifold stylized elements. The injunction to "be yourself," to break free of all stylistic prescriptions, reigns supreme, as a look into any fashion magazine demonstrates. The diktat that is being issued is that the shopper refuse to submit to any diktat, mixing and (mis) matching Chanel with H\&M, vintage YSL with American Apparel, a Cartier watch with flea-market jewelry. The same holds for the interiors: like the wardrobes the featured celebrities allow us to peer into, the unique mixture of styles in their homes supposedly says more about them than a thousand words ever could.

Now, the recent trend toward greater individualization has indeed rendered social codes more permeable. But as it is not simply 
the opposite of the standardization - since algorithmically organized consumer culture paradoxically produces individuality through similarity - this trend by no means implies that the social logic of distinction propelling consumerist taste has been suspended. It has merely undergone further differentiation, but without abolishing the signifiers of status. What is truly exquisite about the subject of taste appropriating itself in consumption now becomes manifest in the constellation of elements. The selection of individual such elements may suspend the old logic of distinction; but their constellation restores it in new form.

Whether espousing Rihanna lends credence to the cultural capital of the person who appropriates the phenomenon she represents depends on what else that person consumes: whether the consumption of Rihanna must be understood as part of a constellation also involving Shakira and "America's Next Topmodel," or finds its place in a mental interior design that also accommodates, say, “The Wire”, Arnold Schönberg, and Didier Eribon. In other words, it is the constellation that determines whether the genuine Louis Vuitton bag looks like the climax of the sad existence of a woman who will never live in the world the bag is meant to embody as though she truly belonged, or the offhand and casual attribute of someone who no longer needs to yearn for that world because she has always already been part of it. The more comprehensive and globalized the cultural spectrum with which an individual is familiar and the greater the individual's financial abilities, the more convincingly he or she will create the impression of having attained confident mastery, exercising a freedom of consumption no longer hobbled by the old distinctions between high and low; the more effective his or her demonstration that he or she is attuned to the most recent developments and therefore himself or herself culturally flexible and marketable. In contrast with the so-called good taste of the old bourgeoisie, this new one seems to be defined even less by the value of the things themselves, emerging instead in pure form: as a faculty of choosing.

Yet the consumerist freedom of choice finds itself constrained by the fact that it essentially responds to what is being offered to it in the world of commodities, which is subject to perennial innovation. In this respect, the flexibility of the subject of contemporary taste is always also an adaptive achievement. Moreover, we would be well advised, it seems to be clear, not to take the fact that we now have the choice from a spectrum of consumerist options that defeats the old distinctions between high and low to be evidence of a democratization of taste. That would be a fallacy, ignoring the 
question of who has access to this spectrum. The new logic of distinction, based on constellations of choices, is no less based on social inequality than the old one. The extent of the spectrum of choices (and hence the market value of the person that makes these choices) is a matter of the individual's financial abilities as well as his cultural literacy.

But is the finding that art appears in this context as the commodity whose very purposelessness recommends it as particularly suited to purposes of social distinction the final, the really true truth about art, as Bourdieu suggests? Art is tradable just like other things-at first blush, that is no more than a simple concomitant effect of the fact that art, too, partakes in the social relations of production. It accordingly participates in the aesthetic ideology when it believes that, as art, it can steer clear of these relations. Art does not exist but as mediated by the commodity form. The most advanced art of the past decades, however, has by no means obliterated this fact. It has renounced the modernist doctrine according to which it would assert its autonomy to the extent that the reflection on its means of representation would become to it an end in itself. As it turned out, art that submitted to this (Greenbergian) diktat of purity was especially apt to degenerate into compliant decoration, the equivalent of a tureen. In response to the ideology of its own institution, art has radically extended the modernist impulse to reflect on its own conditions: such reflection now encompasses not only the conditions implicit to its medium, but also those that govern its presentation, reception, and production. Art that performs such institutional critique points to the social contexts in which it is embedded. Doing so not least importantly also means raising the question of how art is appropriated, and raising it in the medium of art.

Yet the specific critical potential of art consists not solely in its ability to reflect on the social structures in which it participates, but also and especially in how it does so. For that is precisely where its autonomy becomes manifest-an autonomy, however, that must no longer be conceived along the lines of formalist modernism. That is perhaps nowhere more evident than with regard to works that deliberately destabilize the boundary between art and commodity (a tradition that goes back to Warhol). In doing so, they do not in fact undo the difference between art and the commodity, instead compelling us to understand that difference in a fundamentally different way. It is obviously no longer a matter of the distinction between types of objects-as indeed it has become apparent that the idea of locating the autonomy of the aesthetic in specific qualities 
of objects was to no avail when it came to countering the reification that turned the works into executive-floor decoration. It is a matter instead of a difference initiated by artistic procedures of shifting our relation to the respective objects. Art does not confront the world of commodities as a clearly delineated and wholly distinct realm of objects. It accordingly exercises its autonomy not by pretending to a position unsullied by the commodity-form (that would be aesthetic ideology), but instead by setting us in a relation of reflective distance vis-à-vis the commodities that surround us and with which we in fact furnish our identities.

For the subject of consumerist taste continually reappropriates itself in its choice of commodities; the aim is time and again to find oneself afresh amid the changing offerings. The subject of aesthetic experience, by contrast, is referred back to itself to the exact degree that it cannot locate itself in its survey of the objects, that the identificatory relation to them fails, that the automatism of appropriation is disrupted. Consumption turns any new and unfamiliar object into a possession of the subject in order to enrich its identity; the aesthetic, by contrast, aims at the opposite experience, in which even the most familiar objects become strange-the experience, we might say of, an aesthetic expropriation. But as the objects become unfamiliar, the subject, too, becomes strange to itself in its appropriating relation to itself and the world; it becomes strange to itself as a subject of taste. The subject is thus confronted with the social stratum implicit to what is ostensibly most individual to it: its taste.

If we want to remain loyal to an old (Kantian) tradition by extending the term "judgment of taste" to include the aesthetic judgments that rest on such an experience, they identify something about taste that runs exactly counter to consumerist taste: "taste" would in this instance be the name for the ability of this faculty to step outside itself (its own subjectivism) in an act of reflection and to realize that the faddish "pathos of being different" is actually socially enjoined. This happens, however, exactly to the degree that any determinate judgment is suspended in the experience at stake. The aesthetic judgment of taste refers to an experience in which the categories of our evaluative relation to the world become problematic. If there is an implicit relation to community in the aesthetic judgment because it expects "the concurrence of others," it would be the community of those who have become suspect of the self-assurance of their own taste; it would be a community that is precisely not beholden to any identity, but one that exceeds itself through the possibility of challenging itself. That is why, as Adorno once put it, "it is precisely the nerves 
most highly-developed aesthetically that [...] find self-righteous aestheticism intolerable."

In radicalizing this motif already operative in modernist aesthetics but partially occluded by its formalist strands, contemporary explicitly turns against the self-righteous institutionalization of art as a sphere divorced from everything else, for in so doing it at once also turns against the culinary taste of so-called art lovers. It is driven, moreover, by "repugnance for all artistic subjectivism," be it in the guise of narcissistic animation or individual rebellion. For these are the manifestations of the bourgeois subject of taste in the domain of artistic production. Such works accordingly do not generally have to wait long for buyers who will recognize themselves (sensitivity! radicalism!) in them. Instead of aiming at subjective expression, today's most advanced art therefore works to give presence to the objective element within the subjective. However, the respective artistic practices do not do so by suspending the aesthetic in favor of a real space of political or moral action, instead, they insist on the specificity of aesthetic experience. For having an aesthetic experience means, as Martin Seel has put it, experiencing experience, that is: encountering the world of experience familiar from the real world anew in the mode of reflexive distance. This effect comes in because even the most reality-saturated art does not simply merge into life, as if art merely repeated life. Rather, the autonomous life of art consists in a dynamic that negates the unilateralness of formalist approaches or those exclusively oriented to content-a dynamic, and this is important, too, from which the viewer or spectator cannot be exempt. This can be emphatically seen in those works that intensify their relation of tension between form and content to such a degree that both sides, as well as the corresponding approaches, conflict with one another to an intolerable point, but without ever completely liberating themselves from the other side.

In 2000, for instance, the Spanish artist Santiago Sierra exhibited persons who were, or so it seemed, illegally in Germany in cardboard boxes in Berlin's Kunstwerke; at other actions members of the precariat were paid to allow a line to be tattooed on their backs or their hair to be dyed. The possibility of not viewing the works primarily in moral and/or political terms and in relation to the living conditions of the extras who were appearing in them, but as merely staged - and as fictional in the broadest sense - cannot be separated from the work any more than can the connection to the bodily and social reality of its performers. This circumstance triggered moral discomfort among Sierra's audience. He was accused 
of exploiting the performers for a media spectacle. His critics felt that the presumably enlightening aspect of his work should be de facto placed at the level of the pornography of Schadenfreude that is mass produced today for commercial television, in which the reality and liveness of the miserable is little more than fetishized for its sensational appeal. Now of course one could ask whether an art that so obviously expresses the stamp of cynicism is also in fact cynical. This is how the defense of Sierra goes: the artist is merely holding up a mirror to the cynicism in society-and therefore is not himself cynical. This alone, however, does not free Sierra's art from the accusation that it happens in a way that is more part of the problem of exploitation than part of its solution. But this accusation overlooks a decisive factor, namely that by blurring the boundaries between fiction and reality, art and non-art, his works - unlike reality television shows - trouble and make problematic the position of the spectator or viewer himself. The viewer or spectator with Sierra is part of what's happening, and this gives him a certain share in the responsibility for the situation. At the same time, the moral action of freeing the undocumented immigrants from their undignified position under the cardboard boxes, however, runs the risk of committing the same categorical mistake that Stanley Cavell describes in the case of the southern yokel at the theater who storms the stage to free Desdemona from the black man. But pointing out that this is "only" art is obviously not much more instructive. Rather, the point of the work comes precisely from the discomfort generated by a situation that calls into question the security of the spectator's position by turning the boundaries between the aesthetic and the non-aesthetic, art and non-art, fiction and reality, form and content into the object of a doubtlessly serious aesthetic play. Precisely because even those works that emphasize a real always at the same time harbor a moment of semblance, those who participate in them are rebuffed back to themselves, to their behavior, their perception, as well as the social schemes of interpretation at the basis of them. Our participation is reflected in art as a question.

This logic takes hold, as I see it, also and precisely when the aesthetic experience involves strong sensations and feelings. There are doubtlessly a group of artistic works, and not only in the areas of theater and performance, that are intended precisely to invoke such emotional effects in the viewer as shame, disgust, dread, pity, and the like. Because, however, as Alexander García Düttmann insists, the uncontested reality of these feelings breaks down at the same time with the consciousness of semblance, because the 
attention to the mediated quality of art demanded by art conflicts with the immediacy of the emotional reaction that it nonetheless provokes, the mediated quality of the emotions themselves also always comes forth in the experience of such works. One can think of the example of so-called abject art here, an art that works with or evokes materials that are considered contaminative (such as feces, urine, blood, vomit). Correspondingly, this art has often induced reactions of disgust in its viewers, indeed, by the same stroke has triggered discussions in social and cultural studies about the social constructedness of disgust or of the discarded (the abject). Something similar can certainly be said in view of the artistic engagement with the feeling of shame, which plays a role, for instance, in Yoko Ono's Cut Piece.

As can be gleaned in Christiane Voss's philosophical work, emotions, unlike instincts and reflexes, do not belong to a stratum that would lie beneath or before the level of meaning. Rather, emotions themselves are meaningful; they are multiply interwoven with our assumptions about the world. Thus, this means that they are normative social practice mark emotions in a manner that is always conveyed through language. We have learned to feel shame or disgust. And we have learned this in reference to specific situations or objects. Emotions are not independent of the situations or objects that trigger them - nor of our assumptions about them. Interpreting situations and objects is generally what outlines the sense of emotions in the first place. If one didn't know what it was about, or respectively how to interpret what it was about, one would hardly be able to decide what emotional condition one was in. Emotions thus can be traced back to particular evaluations of situations or objects; but the reverse is equally conceivable, that bodily perceptions associated with emotions have an effect on how we assess situations and objects. Only because I turn red do I perceive the situation as shameful; only because my heart pounds do I notice that my relation to $\mathrm{X}$ is not as neutral as I had thought. The objects of our emotions are therefore equally the triggers as well as the products of emotions. In each case, however, the dynamic connection between emotions and an evaluative dimension of perceiving objects and situations cannot be denied.

The connection between emotions and the normative orientations that mark our perception, deep into the affective dimension, is realized in the aesthetic experience with a certain necessity. Due to the dual character of participating in art, our immediate reactions to what is represented remain subject to an opposing attentiveness to the representation that also reflexively distances its 
effects on us. This does not reduce these effects themselves to semblance, but it puts them in a perspective that can become thematized in connection to cultural and social patterns of interpretation. This is exactly why cases in which we experience art to a certain degree on our own bodies (and we become sluggish, turn red, or the like) might even particularly lead to something like an awareness about the socially mediated quality of the seemingly immediate.

By targeting such experiences, the art of the present turns irrefutably explicitly against the idea of a neutrality of the spectator tied to the objectivity of the matter. To conclude, this has once again consequences for the practice of judgment. The shift that is necessary now to think can be explained quite well through the figure of the professional judge, the critic. Traditionally, the critic was imagined as someone who establishes his authority through distance to the object, and this distance was meant to guarantee his neutrality - as if the boundaries of the self and the object were stable. Understood in this way, the ideal critic is not only objective, but also as free as possible from prejudices, he also shows as few affective reactions as possible, above all no strong reactions like shame, excitement, fear, or disgust. In this conception, neutrality is a requirement for the practice of critical judgment. In the last few decades this model of critic has come under enormous pressure from art - be it through polarizing contents which point to the heterogeneity of the art public, that is, to the fact that the experiences made here and the judgments passed here are always already influenced by various social backgrounds; be it through the fact that artistic productions have been targeting an affective loss of distance in the spectator. Both strategies compel us to become aware of the implication of our embodied, empirical subjectivity in the objects of our judgment. This happens, however, exactly to the degree that a determinate judgment is suspended. For the aesthetic judgment refers precisely to an experience in which the categories or our evaluative - affective and/or cognitive - relation to the world become problematic. If there is an implicit relation to community in the aesthetic judgment, to make that point again, it would be the community of those who have become suspect of the self-assurance of their own practice of judgment; their taste. 
1 The text documents a lecture given on the occasion of the Aesthetics Unlimited Conference on Taste (Copenhagen, May 4-5, 2017) for which the author summarized considerations first developed in the following essays: "Some Remarks on the Interior Design of Contemporary Subjectivity and the Possibilities of its Aesthetic Critique," in Interiors, ed. Lynne Cooke, Josiah McElheny, Johanna Burton (Berlin: Sternberg, 2012), 311-317; "Dark Play. Anne Imhofs Abstraktionen," Anne Imhof. Faust, ed. Susanne Pfeffer, Exhibition catalogue, German Pavilion, 57. Biennale di Venezia (Köln: König, 2017), 25-33; "Forms of Participation in Art," in Qui Parle: Critical Humanities and Social Sciences (23.2/2015), 29-54.

2 Pierre Bourdieu, Distinction: A Social Critique of the Judgment of Taste, trans. Richard Nice (Cambridge, Mass.: Harvard University Press, 1984), 280.

3 Ibid., 281.

4 Karl Marx, "Comments on James Mill, Éléments d'économie politique," in Karl Marx and Friedrich Engels, Collected Works, vol. 3 (London: Lawrence and Wishart, 1975), 218.

5 Steffen Zillig, "The Image of the Collector: From Citoyen to Celebrity," Texte zur Kunst 83 (2011), 102-104.

6 "What might be called use value in the reception of cultural assets," Adorno and Horkheimer write, "is being replaced by exchange value; enjoyment is giving way to being there and being in the know, connoisseurship by enhanced prestige [...] Everything is perceived only from the point of view that it can serve as something else, however vaguely that other thing might be envisaged." Theodor W. Adorno and Max Horkheimer, "The Culture Industry: Enlightenment as Mass Deception," in Dialectic of Enlightenment. Philosophical Fragments, trans. Edmund Jephcott, ed. Gunzelin Schmid Noerr (Stanford: Stanford University Press, 2002), 128.

7 Luc Boltanski and Ėve Chiapello, The New Spirit of Capitalism (London and New York: Verso, 2005).

8 Hannah Arendt, The Human Condition, 2nd ed. (Chicago: Chicago University Press, 1998), 211.

9 Ibid., 187-88.

10 On the political-ethical critique of Romanticism in Hegel, Kierkegaard, and Carl Schmitt, see Juliane Rebentisch, The Art of Freedom: On the Dialectics of Democratic Existence, trans. Joseph Ganahl (Cambridge, UK: Polity, 2016).

11 Maurizio Lazzarato, "The Concepts of Life and the Living in the Societies of Control," in Martin Fuglsang and Bent Meier Sørensen, eds., Deleuze and the Social (Edinburgh: Edinburgh University Press, 2006), 171-90, especially p. 178.

12 On the relationship between individualization and style, see also Georg Simmel, "The Problem of Style," in Simmel on Culture, ed. David Frisby and Mike Featherstone (London: Sage, 1997), 215-16.

13 See Christoph Menke, "Ein anderer Geschmack. Weder Autonomie noch Massenkonsum," in Christoph Menke and Juliane Rebentisch, eds., Kreation und Depression. Freiheit im gegenwärtigen Kapitalismus (Berlin: Kadmos, 2010), 232-33.
14 Arthur Danto, however, underestimates Warhol's artistic operations in his approach to the Brillo Box.

Cf. Juliane Rebentisch, Theorien der Gegenwartskunst. Zur Einführung (Hamburg: Junius, 2013), 122-135.

15 Theodor W. Adorno, Minima Moralia. Reflections on a Damaged Life, trans. E.F.N. Jephcott (London: Verso, 2005), 145.

16 Ibid.

17 lbid.

18 See Martin Seel, Die Kunst der Entzweiung: Zum Begriff ästhetischer Rationalität (Frankfurt am Main: Suhrkamp, 1985), $319 \mathrm{f}$.

19 The works are also simply called: Laborers who cannot be payed, remunerated to remain in the interior of carton boxes (Kunst-Werke, Berlin, 2000); $250 \mathrm{~cm}$ Line Tattooed on 6 Paid People (Espacio Aglutinador, Havana 1999); 133 persons paid to have their hair dyed blonde (Arsenale, Venice 2001). The following passage of Sierra is based on Juliane Rebentisch, "Realismus heute: Kunst, Politik und die Kritik der Repräsentation," in WestEnd: Neue Zeitschrift für Sozialforschung, 2, 2010, 15-29, here $20 \mathrm{f}$.

20 On the affinity that a "sensational new realism in the visual arts" at first glance maintains to "new formats in mass media," see also Diedrich Diederichsen, "Realitatsbezüge in der Bildenden Kunst: Subjektkritik, Repräsentationskritik und Statistenkunst," in Realismus in den Künsten der Gegenwart, ed. Dirck Linck/ Michael Luthy/Brigitte Obermayr/Martin Vohler (Berlin: Diaphanes, 2010), 13-28, here $14 \mathrm{f}$.

21 Stanley Cavell, "The Avoidance of Love: A Reading of King Lear," in Must We Mean What We Say? A Book of Essays (Cambridge: Cambridge University Press, 1976), 267-353, here 329.

22 See Alexander García Düttmann, Teilnahme. Bewusstsein des Scheins (Konstanz: Konstanz University Press, 2011), 98-111.

23 See Christiane Voss, Narrative Emotionen: Eine Untersuchung über Möglichkeiten und Grenzen philosophischer Emotionstheorien (Berlin/New York: de Gruyter, 2004).

24 For more on this, see also Christiane Voss, "On the Affective Transformation of Aesthetic Judgment," in Juzgar el arte contemporáneo/Judging Contemporary Art, ed. Juliane Rebentisch (Pamplona: Catédra Jorge Orteiza, Fundació Mapfre, 2012) 187-215.

25 For a feminist critique of this model of (art) criticism, see also Amelia Jones, "Art History/Art Criticism: Performing Meaning," in Performing the Body/Performing the Text, ed. Amelia Jones \& Andrew Stephenson (New York: Routledge, 1999), 39-55, as well as-in reference to Jones-Jennifer Doyle, "The Effect of Intimacy: Tracey Emin's Bad Sex Aesthetics," in Sex Objects: Art and the Dialectics of Desire (Minneapolis: University of Minnesota Press, 2006), 97-120, here esp. 115 f. 